\title{
Developing a clinical pathway for noninvasive ventilation
}

Balfour, L (Mcur) University of Pretoria (RSA), Coetzee, IM (PhD) University of Pretoria (RSA), Heyns, T (PhD) University of Pretoria (RSA)

Corresponding author:

Dr Isabel Coetzee

Lecturer University of Pretoria (South Africa)

Department of Nursing Science

Email: Isabel.coetzee@up.ac.za

Tel nr: +27832761422

Fax nr: +2712 3541490

This article is published based on the research findings from a masters dissertation study.

\section{ABSTRACT}

Lately the use of noninvasive ventilation (NIV) has gained popularity as an alternative to traditional invasive ventilation for the management of patients presenting with acute respiratory failure. This is largely due to the fact that NIV reduces the risks associated with invasive ventilation. The lack of published guidelines for the effective use of NIV has prompted the researchers' interest in the development of a clinical pathway for the use of NIV in adult patients in the critical care unit (CCU). 
The aim of the research was to identify the compulsory components to be included in the clinical pathway and to develop a clinical pathway for NIV. The research design utilised for this study was qualitative, contextual, explorative and descriptive in nature. The study consisted of three phases: Phase 1: Explorative phase Identify the compulsory components of the clinical pathway; Phase 2: Literature control - to confirm the components for inclusion in the clinical pathway; and Phase 3: Development of a clinical pathway for NIV.

A draft clinical pathway was developed based on the findings of Phase 1 and 2. The members of the multidisciplinary team were given an opportunity to comment on the draft clinical pathway. These inputs were included in the development of the final clinical pathway for NIV.

The aims and objectives of the study were realised and culminated in the development of a clinical pathway for NIV which can be implemented in the critical care unit.

\section{Introduction}

Healthcare professionals are constantly under pressure to provide care that is costeffective while maintaining high quality of care. Noninvasive ventilation (NIV) used for the management of respiratory failure in critically ill patients has been reported to have the same efficacy and brings about the same physiological improvement as 
invasive ventilation, while reducing the complications associated with endotracheal intubation ${ }^{3}$.

The most recognised benefit for the use of NIV is the reduction in the complications associated with endotracheal intubation. Avoidance of endotracheal intubation reduces the risk of complications such as ventilator-acquired pneumonia and lung injuries that could lead to extended hospital stay ${ }^{3,4}$. The prevention of these complications could therefore be cost-effective ${ }^{5,6,23}$. The use of NIV at an early stage normally reduces the need for endotracheal intubation ${ }^{7}$. In addition, NIV does not necessitate sedation and reduces the associated risk of sedation. NIV also allows the patient normal activities such as eating, drinking and communication while being ventilated ${ }^{5}$. NIV enhances the patient's comfort and psychological wellbeing ${ }^{8}$.

A clinical pathway guides the healthcare provider to sequence the correct actions at the correct time in order to achieve patients' goals more efficiently, and therefore reduce the cost of hospitalisation and length of stay ${ }^{25}$ In addition, the utilisation of clinical pathways might aid in bridging the gap between knowledge and practice, because as new research evidence becomes available, the clinical pathway is continuously updated. In this way both the patients and the healthcare professionals benefit from new developments in healthcare ${ }^{26}$.

It is the opinion of Elliott ${ }^{6}$ that noninvasive ventilation is underutilised. The underutilisation of NIV can be attributed to several factors. Firstly, NIV is a 
relatively new mode of mechanical ventilation and there is a degree of uncertainty about its use, as well as the perceived added workload associated with the initiation of NIV ${ }^{6}$. Secondly, although there are many studies stating the benefits of NIV ${ }^{6,9,10}$, there are no published guidelines (clinical pathway) regarding the utilisation of NIV in critical care units ${ }^{3,11}$.

Several studies have been conducted to establish the effectiveness and safety of NIV, but healthcare professionals still do not concur about the appropriate implementation of NIV ${ }^{19,21,26}$. Despite the advantages of using NIV, healthcare professionals are not in agreement about precisely when to commence NIV ${ }^{20,22}$. Therefore the aim of this article is to illustrate the development of a clinical pathway for NIV. The development of a clinical pathway for NIV could guide healthcare professionals regarding the initiation and the management of patients receiving NIV. This in turn would be beneficial to patients, due to the reduced risks involved in this mode of mechanical ventilation. In addition, a clinical pathway may enhance the collaboration of healthcare professionals and improve the quality of care delivered ${ }^{12,26}$.

\section{Setting}

The study was conducted in a critical care unit (CCU) of a private hospital in the Gauteng province of South Africa. The hospital has a total of 205 beds, of which 20 are dedicated critical care beds. Of these beds, 14 are primarily for the admission of general medical critically ill adult patients. The other six beds are dedicated to trauma patients and critical ill surgical adult patients, including patients undergoing 
general surgery, cardiothoracic surgery and maxillofacial surgery. In total, 27 nurse practitioners work in the CCU. Additional multidisciplinary team members involved in the $\mathrm{CCU}$, specifically with regard to mechanical ventilation, are two physicians, one cardiothoracic surgeon and two physiotherapists. The dietary needs of the critically ill patients are addressed by the dietician who sees each patient on a daily basis.

\section{METHOD}

A qualitative, contextual, explorative and descriptive research design ${ }^{13,14}$ was utilised. Qualitative research designs are used when there is a need for an in-depth investigation of the phenomenon of interest which requires the use of a flexible research design ${ }^{13,16,18}$, hence this approach was adopted to explore the components of and develop a clinical pathway for NIV.

The research was comprised of three phases. During Phase 1 (explorative phase), the components for inclusion in the clinical pathway for NIV were identified. During Phase 2 (literature control) the data collected (components for inclusion) was verified through an in-depth literature control. During Phase 3 (developmental phase) a draft clinical pathway was developed, based on the findings of Phases 1 and 2. The draft clinical pathway was distributed to the participants for written inputs and feedback on the draft document. These inputs were included during the refinement of the draft clinical pathway. The final clinical pathway was given to two experts in the field of ventilation of critically ill patients for validation and feedback. 


\section{Sample}

Purposive sampling was utilised for the selection of participants for Phase 1 of the study ${ }^{13}$.The criteria for inclusion as a participant in the study were that the participant (i) was required to be a member of the multidisciplinary team currently working in the $\mathrm{CCU}$, (ii) needed to have had previous experience with utilisation of NIV, and (iii) had to be a nurse practitioner, physiotherapist or physician. Phase 3 included the same participants from Phase 1. Furthermore, snowball sampling was used in an effort to verify the final clinical pathway.

\section{Sample characteristics}

During Phase 1 a total of 15 participants participated in the group discussion. The 15 participants included 13 nurse practitioners with various nursing qualifications and expertise in both invasive and noninvasive ventilation, and 2 participants were clinical respiratory technologists specialising in mechanical ventilation.

The sample utilised during Phase 3 of the study included a total of 20 participants who participated voluntarily. The participants were comprised of 14 nurse practitioners, 2 clinical respiratory technologists, 2 physiotherapists and 2 physicians.

\section{Data collection}

In the context of qualitative research, a group discussion constitutes a form of focus group interview, and is considered to be highly effective in generating rich data, which is further enhanced by the interaction between the group

members ${ }^{15,16,17}$. The participants were divided into four groups prior to the onset of 
the group discussion. Each individual group member had time to write down her own ideas pertaining to the components of a clinical pathway for non-invasive ventilation. Each group then had time to discuss in the individual groups the ideas they had written down, and to come up with a draft of components as concluded by each group.

Each individual group then had an opportunity to share the members' ideas with the other groups. After having received feedback from the various groups, each group recorded their ideas on a white board. Once all the groups had given feedback, a group discussion involving the participants of all four groups was held to reach consensus on which of the recorded components written would be compulsory components for the clinical pathway for NIV. The data collected from the groups' consensus discussions was verified by means of a comprehensive literature control (Phase 2), and a draft clinical pathway was compiled based on the findings of Phase 1 and 2 . The draft document was distributed to the participants for inputs and refinement of the draft document. Inputs from all participants were incorporated during Phase 3 for the development of the final clinical pathway for NIV.

\section{RESULTS}

The compulsory components for inclusion in the clinical pathway for NIV, identified during the consensus group discussion and verified from the literature control, are summarised in Table 1. 
Table 1 Summary of the themes, categories and sub-categories of Phase 1 and Phase 2

\begin{tabular}{|c|c|c|}
\hline Theme & Categories & Sub-categories \\
\hline \multirow[t]{18}{*}{ Assessment } & \multirow{3}{*}{ History } & Age \\
\hline & & Underlying pathology \\
\hline & & Social history \\
\hline & Prognosis & \\
\hline & Acuity of illness/injury & \\
\hline & Inclusion criteria & \\
\hline & \multirow{8}{*}{ Exclusion criteria } & Abdominal distension \\
\hline & & Acute myocardial infarction \\
\hline & & Asthma \\
\hline & & Congestive heart failure \\
\hline & & Facial injuries, fractures and/or abnormalities \\
\hline & & Gastrointestinal bleeding or - surgery \\
\hline & & Haemodynamically unstable patients \\
\hline & & Surgery to the upper airway \\
\hline & \multirow{4}{*}{ Systems-oriented assessment } & Central nervous system \\
\hline & & Respiratory system \\
\hline & & Cardiovascular system \\
\hline & & Diagnostic tests \\
\hline \multirow[t]{6}{*}{ Planning } & Equipment & \\
\hline & Patient safety & \\
\hline & Ventilator settings & \\
\hline & \multirow{3}{*}{ Patient monitoring } & Haemodynamic monitoring \\
\hline & & Arterial blood gas \\
\hline & & Patient comfort \\
\hline \multirow[t]{4}{*}{ Implementation } & \multirow{4}{*}{ Holistic patient care } & Patient education \\
\hline & & Spiritual needs \\
\hline & & Multidisciplinary team approach \\
\hline & & Specific observations \\
\hline Evaluation & & \\
\hline
\end{tabular}


Each of the components of the themes, categories and sub-categories is discussed briefly in the following section.

\section{DISCUSSION}

The four themes were based on the nursing process that were utilised as the conceptual framework for this research. Consensus was reached regarding the categories and sub-categories presented during Phase 1 of the research. A discussion relating each theme, category and sub-category is provided.

\section{Assessment}

The assessment of the patient's suitability for NIV is paramount to its successful application to the adult patient presenting with acute respiratory failure. From the assessment and data collected the researcher established that certain patient groups are favoured for treatment with NIV owing to certain preconceived ideas related to NIV. The lack of defining criteria for the inclusion of patients for treatment with NIV means that patients who might do well with NIV are often invasively ventilated, despite the obvious risks involved.

Inclusion and exclusion criteria need to be defined before the implementation of a treatment plan. The assessment of the patient is vital to the success of NIV, and should be carried out by skilled healthcare professionals. Patients should be assessed individually and the treatment goals should be established for each individual patient. 


\section{$\Rightarrow$ History}

The determination of the treatment goals for the specific patient is facilitated by establishing the health history of the patient. Establishing the co-morbidities and risk factors present on admission to $\mathrm{CCU}$, will guide the multidisciplinary team to set patient-specific treatment goals, for example the patient who does not wish to be invasively ventilated or to have his or her life prolonged with artificial means. Determining the history of the patient will also guide clinical decision-making regarding the mode of ventilation and the specific patient needs to ensure optimal therapeutic levels of NIV.

\section{- $\quad$ Age}

Age was not considered to be a determinant for the use of NIV in the specific research setting as indicated in the literature. For this reason, the researcher deemed it unnecessary to include age as a parameter in this clinical pathway ${ }^{27}$. The use of NIV in acute respiratory failure as a result of diverse pathologies and related aetiologies has been described in the literature. Patients who undoubtedly benefit from NIV are patients with chronic obstructive pulmonary disease and immunecompromised patients ${ }^{19,} 20$.

\section{- Social history}

Determining the social history of the patient prior to the commencement of NIV will assist the multidisciplinary team in identifying potential problems that could lead to the failure of NIV, for example intolerance of the mask and uncooperative patient 
behaviour due to withdrawal symptoms. The potential problems can be prophylactically managed to prevent the failure of NIV due to these factors ${ }^{28}$.

\section{$\Rightarrow$ Prognosis}

Prognosis should not be a determinant for the management of a patient with NIV. NIV is the 'superior' alternative to invasive ventilation and the wishes of the patient and relatives should always be taken into consideration when planning care. NIV has a definite role to play in palliative care - supporting the dying patient regardless of the outcome. The treatment goals should, however, must be clearly stated before commencing NIV 5 .

\section{$\Rightarrow$ Acuity of illness/injury}

Certain patient groups are not suited to NIV. These include trauma patients (due to the severity of traumatic injuries) and patients with facial burns, facial fractures or facial abnormalities that impair mask fit. These patients should be managed with invasive ventilation without hesitation ${ }^{29}$.

The individual assessment of a patient's suitability for NIV cannot be overemphasised. Certain groups of patients (e.g. COPD) should not be excluded from NIV simply because of preconceived ideas harboured by members of the multidisciplinary team ${ }^{30,40}$. 


\section{$\Rightarrow$ Exclusion criteria}

An altered level of consciousness is one of the main predictors of failure of NIV. Patients with an altered level of consciousness who are unable to protect their airway should not be considered for NIV ${ }^{31}$. Patients with altered cough and gag reflex should be managed with extreme caution when using NIV, due to the increased risk of aspiration ${ }^{9}$.

Participants reached consensus that specific exclusion criterion for NIV should be stipulated. The exclusion criteria are the following:

- Abdominal distension

- Acute myocardial infarction ${ }^{32}$

- Asthma ${ }^{33}$

- Congestive heart failure ${ }^{34}$

- Facial injuries, fractures and/or abnormalities ${ }^{31}$

- Gastrointestinal bleeding or - surgery ${ }^{31}$

- Haemodynamic instability ${ }^{35}$

- Surgery to upper airway and/or gastrointestinal tract ${ }^{34}$

To enable the critical care nurse practitioner to assess the patient for suitability for NIV, a comprehensive assessment should be done on the central nervous system, the respiratory system and the cardiovascular system, as discussed below. 


\section{$\Rightarrow$ Systems-oriented assessment}

A complete systems-oriented assessment of the patient should be done at fourhourly intervals. Assessment of the central nervous system should be done to determine the level of consciousness. The Glasgow Coma Scale may be used as a guideline to establish the patient's suitability for NIV. If the patient remains awake and able to comprehend and cooperate with the nurse practitioner, NIV may be used $^{36}$.

The respiratory system assessment should include observing for signs of respiratory distress, including the use of accessory muscles, nasal flaring, signs of cyanosis, increased respiratory rate, and auscultation of the lung fields. A chest Xray should be done at the baseline to assess for signs of pneumothorax or haemothorax, acute lung injury and consolidation ${ }^{9}$.

The assessment of the cardiovascular system should include routine observations of blood pressure, heart rate and rhythm, and peripheral perfusion. Owing to the potential alterations in cardiac output associated with NIV, the nurse practitioner should monitor for changes in these parameters in order to prevent adverse effects $^{31}$.

\section{Planning}

The following section provides a summary of the data collected from the individual groups as well as a summary of the data on which consensus was reached during the group discussion pertaining to the planning for NIV. 


\section{$\Rightarrow$ Equipment}

It was generally agreed that the use of a humidifier is mandatory to prevent adverse effects e.g. mucus plugs, in the patient and to enhance patient comfort ${ }^{37}$.

\section{$\Rightarrow$ Patient safety}

There is concern for the safety of the patient with regard to the application of NIV equipment by inexperienced nurse practitioners. The continuous education of the nurse practitioners in the CCU with regard to NIV is vital to its successful and safe application. Education and training should be provided on an ongoing basis to assess the level of skill of nurse practitioners and to enhance their competency and consequently patient safety ${ }^{38}$.

The added workload associated with the commencement of NIV should be addressed. Current practice does not allow for the allocation of one nurse practitioner to one patient for the application of NIV. Consequently, the potential benefits of the correct and timely application of NIV might be lost owing to inappropriate staffing. The participants agreed that the staffing ratio needs to be revised to allow one nurse practitioner to one patient for the first 48 hours to enhance favourable patient outcomes ${ }^{38}$.

\section{$\Rightarrow$ Ventilator settings}

Patient tolerance is a major determinant of the success of NIV and ventilator settings should be adjusted accordingly. Consensus regarding specific ventilator 
settings was reached, and it was determined that the settings should be according to patient needs and patient tolerance?

The current mode of choice in the CCU is Bi-level positive airway pressure (BiPAP), as this mode is best tolerated by patients. Patient synchrony with the ventilator can easily be acquired with this mode of ventilation. During the initiation of NIV the setting for $\mathrm{FiO}_{2}$ should not exceed $50 \%$. This can be titrated according to patient response which is evident from the arterial blood gas analysis performed at baseline and again after two hours of NIV. Pressure support is initially set at $8 \mathrm{cmH}_{2} \mathrm{O}$ and can be adjusted to enhance patient comfort and tolerance ${ }^{30}$.

\section{$\Rightarrow$ Patient monitoring}

Patients presenting with acute respiratory failure require admission to the CCU owing to the risks involved. In the $\mathrm{CCU}$ environment routine monitoring of the patient is done hourly and any alteration in a patient's health status can be proactively managed ${ }^{31}$.

\section{- Haemodynamic monitoring}

The haemodynamic monitoring of the patient should be done continuously to observe for any adverse reactions to NIV. Monitoring and recording of vital signs should be done hourly and alterations reported to the attending physician without delay $^{31}$.

\section{- $\quad$ Arterial blood gas}


A baseline arterial blood gas measurement should be done prior to commencing NIV. The arterial blood gas values should be reassessed after at least 30 minutes of NIV to establish whether any physiological improvement has occurred. The clinical pathway guides the actions of the multidisciplinary team according to the values obtained from the arterial blood gas analysis ${ }^{39}$.

Using the clinical pathway will ensure that patients receive the correct intervention at the correct time without unnecessary delays that could prove fatal.

\section{- $\quad$ Patient comfort}

Patient comfort during NIV is a major predictor of the success or failure of NIV. The literature suggests that the patient be placed in a semi-recumbent position at $45^{\circ}$ to promote patient comfort and minimise air leaks that cause poor mask tolerance. The patient should therefore be placed in a semi-fowlers position to promote comfort and lung expansion. The mask size should be determined prior to attaching the mask to the patient's head. The size of the mask can be determined using the manufacturer's guidelines for sizing to ensure a comfortable fit with minimal air leaks. The presence of naso-gastric tubes and dentures which may impair mask fit and lead to air leaks should be anticipated and managed in the clinical setting ${ }^{30,40}$.

The formation of pressure sores, particularly on the bridge of the nose, is a risk due to the pressure exerted during NIV and improper application of the face mask. The mask should fit the patient comfortably and the head straps should be fastened tightly enough to seal the mask but without excessive pressure which could cause 
skin breakdown and pressure sore formation. The assessment of the pressure areas should be done at least hourly and prophylactic action taken to prevent skin breakdown, for example by using a barrier cream and pressure relieving dressings to reduce the risk of pressure sore formation ${ }^{28}$.

\section{Implementation}

The following section provides a summary of the data collected from the individual groups as well as a summary of the data on which consensus was reached during the group discussion pertaining to the implementation of NIV.

\section{$\Rightarrow$ Holistic patient care}

The patient and his/her relatives need to be informed and reassured at all times. During the planning for NIV the treatment goals should be established in collaboration with the patient and relatives. The specific needs of the patient and relatives should guide the multidisciplinary team in this respect ${ }^{41,42}$.

\section{- Patient education}

One of the major advantages of NIV is the patient's ability to communicate normally. This provides an opportunity for the nurse practitioner to reassure the anxious patient continuously and to provide the patient with health education and an explanation of the procedure. 


\section{$\Rightarrow$ Initiation of noninvasive ventilation}

The specific needs of the patient should be addressed and therefore it is recommended that the use of NIV be tailored to the specific patient and not be generalised. Patient tolerance and compliance can be enhanced by ensuring patient-specific settings for NIV.

\section{- Multidisciplinary team approach}

The clinical pathway was developed to include the members of the multidisciplinary team currently active in the $\mathrm{CCU}$, including physicians, nurse practitioners, physiotherapists and dieticians. The involvement of the entire multidisciplinary team is paramount to the successful application of NIV and to ensure enhanced patient outcomes. Hence, it is essential to ensure the collaboration of all members of the multidisciplinary team ${ }^{7,43}$.

\section{EVALUATION}

Consensus was reached that continuous monitoring of the patient is essential and that the patient should be closely observed for signs of failure of NIV in order to invasively ventilate the patient timely. Diagnostic tests should be done according to patient-specific needs.

All the discussed themes, categories and sub-categories were incorporated in the design of the final clinical pathway. The final clinical pathway is depicted in Figure 


\section{Clinical pathway for non-invasive ventilation}
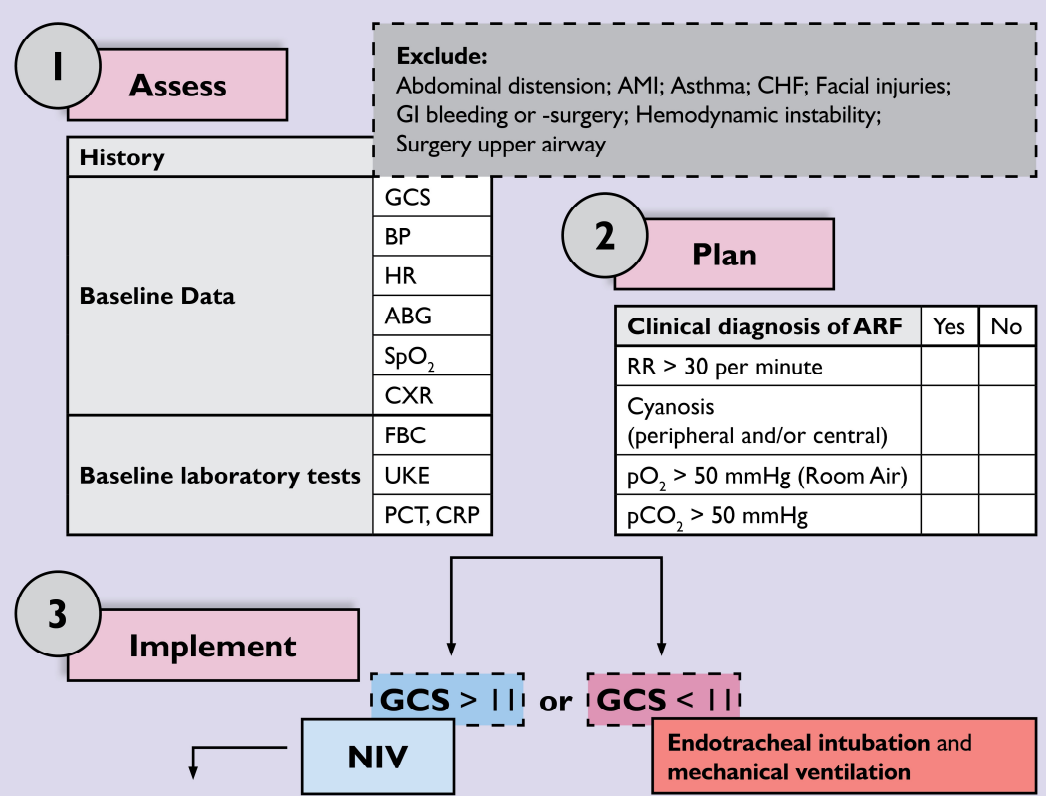

\begin{tabular}{|c|c|c|c|c|c|}
\hline \multicolumn{2}{|c|}{ Mode } & BiPAP & \multicolumn{2}{|c|}{ Base Flow } & 10 \\
\hline \multicolumn{2}{|l|}{$\mathrm{FiO}_{2}$} & 0.5 & \multicolumn{2}{|c|}{ Sensitivity } & -2 \\
\hline \multicolumn{2}{|l|}{ PS } & $8 \mathrm{cmH}_{2} \mathrm{O}$ & \multicolumn{2}{|c|}{ Enter "sync" } & $50 \%$ \\
\hline \multirow{2}{*}{ PEEP } & high & $15 \mathrm{cmH}_{2} \mathrm{O}$ & \multirow{2}{*}{ Time } & high & $3 \mathrm{sec}$ \\
\hline & low & $5 \mathrm{cmH}_{2} \mathrm{O}$ & & low & $3 \mathrm{sec}$ \\
\hline
\end{tabular}

\section{$\longrightarrow$ \\ Patient Preparation}

- Explain procedure to patient

- Patient "awake and willing"

- Elevate head of bed $45^{\circ}$

- Establish patent IV access

- Fit mask

$\sqrt{10}$

- Continuous monitoring of level of consciousness and vital signs - Monitor for signs of increased respiratory distress

4 Evaluate 1 Repeat ABG after $\mathbf{3 0}$ minutes following the initiation of NIV

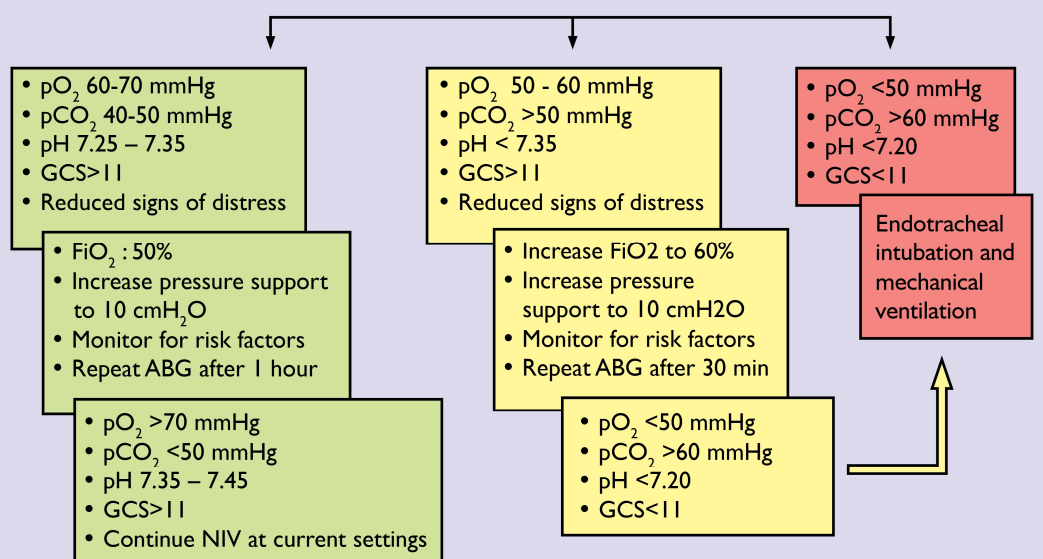

\section{Figure 1 A clinical pathway for NIV}


In Table 2 the relevant abbreviations utilised in the clinical pathway will be indicated.

Table 2 Abbreviations for the clinical pathway for NIV

\begin{tabular}{|l|l|}
\hline \multicolumn{2}{|l|}{ List of abbreviations } \\
\hline ABG & $\begin{array}{l}\text { Arterial blood gas } \\
\text { Acute my }\end{array}$ \\
\hline BiPAP & $\begin{array}{l}\text { Bi-level /Bi-phasic positive airway } \\
\text { pressure }\end{array}$ \\
\hline BP & $\begin{array}{l}\text { Blood pressure } \\
\text { CHF }\end{array}$ \\
\hline CXR & Chest x-ray (portable) \\
\hline FiO 2 & Fractional inspired oxygen \\
\hline GCS & Glasgow Coma Scale \\
GI & Gastro-intestinal \\
\hline HR & Heart rate \\
\hline PEEP & Positive end-expiratory pressure \\
\hline PS & Pressure support \\
\hline RR & Respiration rate \\
\hline SeC & Seconds \\
\hline SpO & \\
\hline & Peripheral oxygen saturation \\
\hline
\end{tabular}




\section{RECOMMENDATIONS}

The most important recommendation made in this article is that the developed clinical pathway for NIV in the critical care practice be implemented and evaluated. Other recommendations relating to the clinical practice, management, nursing education and future research are discussed in the paragraphs to follow.

\section{$\Rightarrow$ Clinical practice}

Clinical pathways are a new concept in clinical practice in South Africa. Current clinical practices do not make use of clinical pathways, therefore the recommendations are that healthcare professionals:

- keep up with international best practices through the development, implementation and evaluation of clinical pathways, and

- involve the members of the multidisciplinary team in the development of clinical pathways to enhance favourable patient outcomes.

\section{$\Rightarrow$ Management}

Although the benefits of implementing clinical pathways have been demonstrated in the literature, in the current South African healthcare society the use of clinical pathways is relatively unknown. The support from hospital management is a vital aspect for the successful development and implementation of clinical pathways.

\section{$\Rightarrow$ Quality improvement}

The development, implementation and evaluation of clinical pathways are recommended to: 
- enhance the standardisation of healthcare delivery to patients;

- decrease discrepancies, which in turn may reduce the number of legal claims related to patient care in the hospital environment;

- meet the expectations of patients pertaining to quality care as the broad access of patients to information means that patients today are well informed and have preconceived ideas related to healthcare delivery; and

- enhance collaboration between multidisciplinary team members which in turn may maintain and increase customer satisfaction.

\section{$\Rightarrow$ Nursing education}

It is suggested that the following actions be implemented in nursing education:

- Address the knowledge gaps and the need for continuous professional development of nurse practitioners pertaining to the development, implementation and evaluation of clinical pathways.

- Ensure that nurse practitioners gain the required knowledge, skills and attitudes to implement NIV successfully.

- Promote in-service training programmes with regard to NIV and the correct application of the clinical pathway.

\section{LESSONS LEARNED}

The most important lessons learned from developing a clinical pathway for noninvasive ventilation are the:

- value of collaboration (team work) with healthcare professionals

- fact that developing a clinical pathway is time consuming 
- importance of continuous education and training pertaining to the development and implementation of the pathway.

\section{REFERENCES}

1. Gedeon A. Mechanical ventilation: A historical perspective. Clinical Window Web Journal 2006; 22:[1-5].

2. Dasta JF, McLaughlin TP, Mody SH \& Piech CT. Daily cost of an intensive care unit day: The contribution of mechanical ventilation. Critical Care Medicine 2005; 33(6):1266-1271.

3. Winck JC, Azevedo LF, Costa-Pereira A, Antonelli M, et al. Efficacy and safety of non-invasive ventilation in the treatment of acute cardiogenic pulmonary edema - a systematic review and meta-analysis. Critical Care 2006; 10:R69.

4. Antonelli M \& Bello G. Noninvasive mechanical ventilation during the weaning process: Facilitative, curative or preventive? Critical Care 2008; 12:136.

5. Baudouin S, Blumenthal S, Cooper B, Davidson C, et al. Non-invasive ventilation in acute respiratory failure. Thorax 2002; 57:192-211.

6. Elliott WM, Confalonieri M \& Nava S. Where to perform noninvasive ventilation? European Respiratory Journal 2002; 19:1159-1166.

7. Agarwal R, Gupta R, Aggarwal AN \& Gupta D. Noninvasive positive pressure ventilation in acute respiratory failure due to COPD vs other causes: effectiveness and predictors of failure in a respiratory ICU in North India. International Journal of COPD 2008; 81: 637-643.

8. Metha S \& Hill NS. Noninvasive ventilation. American Journal of Respiratory Critical Care Medicine 2001; 163:540-577. 
9. Brochard L, Mancebo J \& Elliott WM. Noninvasive ventilation for acute respiratory failure. European Respiratory Journal 2002; 19:712-721.

10. Antonelli M, Pennisi MA \& Montini L. Clinical review: Noninvasive ventilation in the clinical setting - experience from the past 10 years. Critical Care 2005; 9(1):98-103.

11. Curtis JR, Cook DJ, Sinuff T, White DB, Hill N, et al. Noninvasive positive pressure ventilation in critical and palliative care settings: understand the goals of therapy. Critical Care Medicine 2007; 35(3):932-939.

12. Lombardo B, Brindgeman TV, De Michaelis N \& Nunez M. An academic medical centre's programme to develop clinical pathways to manage healthcare: Focus on acute decompensated heart failure. Journal of Integrated Care Pathways $2008 ; 12: 45-55$.

13. Polit DE \& Beck CT. Nursing Research: Generating and assessing evidence for nursing practice, $8^{\text {th }}$ ed. 2008; Philadelphia, Lippencott, Williams \& Wilkens.

14. Polit DE \& Beck CT. Essentials of nursing research: Appraising evidence for nursing practice, $7^{\text {th }}$ ed. 2010; Philadelphia: Lippencott, Williams \& Wilkens.

15. Polit DE, Beck CT \& Hungler BP. Essentials of nursing research: methods, appraisals and utilisation, $5^{\text {th }}$ ed. 2001; Philadelphia: Lippencott, Williams \& Wilkens.

16. Burns N \& Grove SK. Understanding nursing research: Building an evidencebased practice. $6^{\text {th }}$ ed. 2009; Missouri: Elsevier.

17. Creswell JW. Qualitative inquiry \& research design: Choosing among five approaches. $2^{\text {nd }}$ ed. 2007; Thousand Oaks: Sage. 
18. Gillis A \& Jackson W. Research for nurses: Methods and interpretation, 2002; Philadelphia: F.A. Davis Company.

19. Antonelli M, Pennisi MA \& Conti G. New advances in the use of noninvasive ventilation for acute hypoxaemic respiratory failure. European Respiratory Journal 2003; 22(42):65s-71s.

20. Elliott WM, Confalonieri M \& Nava S. Where to perform noninvasive ventilation? European Respiratory Journal 2002; 19:1159-1166.

21. Garpestad E \& Hill NS. Noninvasive ventilation for acute lung injury: How often should we try, how often should we fail? Critical Care 2006; 10:147-148.

22. Lightowler JV, Wedzicha JA, Elliott MW \& Ram FSF. Non-invasive positive pressure ventilation to treat respiratory failure resulting from exacerbations of chronic obstructive pulmonary disease: Cochrane systematic review and metaanalysis. British Medical Journal 2003; 326:[1-5].

23. Metha S \& Hill NS. Noninvasive ventilation. American Journal of Respiratory Critical Care Medicine 2001; 163:540-577.

24. Maggiore SM, Richard JM, Abroug F, Diehl JL, et al. A multicenter, randomised trial of noninvasive ventilation with helium-oxygen mixture in exacerbations of chronic obstructive lung disease. Critical Care Medicine 2010; 38(1):145-151.

25. Rotter $\mathrm{T}$, Kugler J, Koch $\mathrm{R}$, Gothe $\mathrm{H}$, et al. A systematic review and metaanalysis of the effects of clinical pathways on length of stay, hospital costs and patient outcomes. BMC Health Services Research 2008; 8:265.

26. Kurtin P \& Stucky E. Standardize to excellence: Improving the quality and safety of care with clinical pathways. Pediatric Clinics of North America 2009; 56(4):893-904. 
27. Brochard L, Mancebo J \& Elliott MW. Noninvasive ventilation for acute respiratory failure. European Respiratory Journal 2002; 19:712-721.

28. Robert D \& Argaud L. Clinical review: Long-term noninvasive ventilation.Critical Care 2007; 11:210.

29. Wysocki M \& Antonelli M. Noninvasive mechanical ventilation in acute hypoxaemic respiratory failure. European Respiratory Journal 2001; 18:209220.

30. Khilnani GC \& Banga A. Noninvasive ventilation in patients with chronic obstructive airway disease. International Journal of COPD 2008; 3(3):351357.

31. Penuelas O, Frutos-Vivar F \& Esteban A. Noninvasive positive-pressure ventilation in acute respiratory failure. Canadian Medical Association Journal 2007; 177(10):1211-1218.

32. Peter JV, Moran JL, Phillips-Hughes J, Graham, P, et al. Effect of non-invasive positive pressure ventilation (NIPPV) on mortality in patients with acute cardiogenic pulmonary oedema: A meta-analysis. Lancet 2006; 367:11551163.

33. Norwak R, Corbridge T \& Brenner B. Noninvasive ventilation. Journal of Emergency Medicine 2009; 37(S2):S18-S22.

34. Hill NS. Noninvasive positive pressure ventilation for respiratory failure caused by exacerbations of chronic obstructive pulmonary disease: A standard of care? Critical Care 2003; 7(6):400-401.

35. Endorf FW \& Dries DJ. Noninvasive ventilation in the burned patient. American Burn Association 2010; 31(2):217-228. 
36. Scarpazza P, Incorvaia C, Di Franco G., Raschi S, et al. Effect of noninvasive ventilation in elderly patients with hypercapnic acute-on-chronic respiratory failure and do-not-intubate order. International Journal of COPD 2008; 3(4):797-801.

37. Schönhofer B \& Sortor-Leger S. Equipment needs for noninvasive mechanical ventilation.European Respiratory Journal 2002; 20:1029-1036.

38. Ambrosino N. \& Vagheggini G. Noninvasive positive pressure ventilation in the acute care setting: Where are we? European Respiratory Journal 2008; 31(4):874-886.

39. Carron M, Freo U, Zorzi M \& Ori C. Predictors of failure of noninvasive ventilation in patients with severe community-acquired pneumonia. Journal of Critical Care 2010; 25(3):e9-14.

40. Diaz $O$, Bégin $P$, Andresen $M$, Prieto ME, et al. Physiological and clinical effects of diurnal noninvasive ventilation in hypercapnic COPD. European Respiratory Journal 2005; 26(6):1016-1023.

41. Suddarth D. The Lippencott manual of nursing practice. $5^{\text {th }}$ ed. 1991. Philadelphia: Lippencott.

42. Qwan K. The nursing process. 2007. Available at: http://www.thenursingsite.com. Accessed: 05/06/2012.

43. MacIntyre $\mathrm{N} \&$ Huang $\mathrm{YC}$. Acute exacerbations and respiratory failure in chronic obstructive pulmonary disease. American Thoracic Society 2008; 5:530-535. 